\title{
As respostas de Berkeley ao ceticismo
}

Plínio Junqueira Smith

Universidade São J udas Tadeu

resumo 0 artigo compara alguns aspectos da refutação do ceticismo nos Prinápios e nos Três diálogos. Embora normalmente não se veja nenhuma diferença importante entre essas obras, duas hipóteses são defendidas aqui: de um lado, Berkeley desloca o foco de sua crítica das idéias abstratas para a noção de matéria e, de outro, muda sua estratégia de combate, da enunciação imediata da verdade para a lenta elaboração das consequências céticas da noção de matéria.

palavras-chave ceticismo - imaterialismo - matéria - idéia abstrata - sentidos - razão

\section{Introdução}

Por influência do próprio Berkeley, sempre se consideraram os Três diálogos como uma versão mais elegante, porém filosoficamente mais pobre, dos Prinápios. No "Prefácio" aos Três diálogos, Berkeley reconhece que, antes de publicar a nunca publicada e perdida segunda parte dos P rinápios, era "necessário tratar mais claramente e mais completamente certos princípios postos na primeira, e colocá-los em uma nova luz. Esse é o propósito dos D iálogos que se seguem" (BER KELEY, 1998b, Prefácio, 167, p. 55). É "da maneira mais fácil e familiar" (idem, Prefácio, p. 66, 168) que Berkeley pretende introduzir em nossas mentes as noções expostas nos Prinápios. Berman $(1996$, p. 6) expressa de maneira cristalina como essas indicações de Berkeley foram lidas por boa parte dos comentadores. "O próximo projeto de Berkeley era reescrever de modo popular a sua

R ecebido em novembro de 2004. A ceito em janeiro de 2005.

doispontos, Curitiba, vol. 1, n. 2, p. 35-55, jan/ jun, 2005 
posição imaterialista. Acreditando que seus Prinćpios foram rejeitados parcialmente por causa do estilo e apresentação, ele reformulou a obra nos Três diálogos entre H ilas e F ilonous (Londres, 1713). Enquanto os T rês diálogos são mais elegantes e acessíveis e podem ser lidos como pura literatura, eles devem dar lugar aos Prinápios como a versão com autoridade de sua filosofia". . C abe, desde logo, reconhecer a força dessa interpretação. N ão há dúvida de que os Três diálogos são mais el egantes, mais restritos nos tópicos abordados e mesmo mais agradáveis de ler do que os Prinápios. N o entanto, Berkeley também diz que os Três diálogos apresentam "uma nova luz" sobre 0 assunto a ser tratado. Q ue significará isso? Q uais mudanças são indicadas aqui? E qual a sua importância?

U m dos principais objetivos de Berkeley era refutar os céticos'1. A pesar de ele manifestar claramente esse objetivo nos subtítulos de duas de suas obras mais importantes, pouca atenção foi- Ihe dispensada. N ão é, naturalmente, minha intenção aqui tratar da questão do ceticismo em Berkeley de maneira completa, mas eu gostaria de focalizar alguns aspectos centrais e mais gerais da crítica de Berkeley ao ceticismo. Por meio de uma análise da refutação do ceticismo levada a cabo em cada uma dessas obras, inves tigarei se e até que ponto os Três diálogos não passam de uma versão simplificada dos Prinápios. M enos do que uma interpretação detalhada, 0 que se segue deve ser lido como algumas pistas, sugestões e hipóteses de leitura, que demandam uma discussão mais rigorosa e detalhada. Confesso não estar intei ramente persuadido de minhas sugestões e hipóteses, mas, ainda assim, não me parece inútil publicá las, visto que, mesmo se superficiais ou erradas, poderão servir como um auxílio para aprofundarmos nossa compreensão da filosofia de Berkeley. Entre essas sugestões e hipóteses que formularei, cabe destacar, desde já, as seguintes: (1) Berkeley refaz seu diagnóstico da causa do ceticismo e, portanto, desloca o foco de sua crítica: das idéias abstratas para a noção de matéria e (2) Berkeley muda de estratégia de combate: da enunciação imediata da verdade para a lenta elaboração das consequências céticas da noção de matéria².

\section{A concepção de ceticismo}

a) O s P rinápios não oferecem uma definição clara e explícita do ceticis- 
mo, mas não é difícil perceber, em linhas gerais, o que Berkeley entende por "ceticismo". Berkeley abre os P rinápios (BER KELEY, 1998a, I, p. 1) descrevendo a origem do ceticismo, a desconfiança com relação aos sentidos, ao conhecimento propiciado pelos sentidos. C eticismo, nesse parágrafo inicial, não consiste senão em um certo desespero que resulta da filosofia, que se separa dos sentidos e do instinto para aderir a um princípio superior, o da razão, quando tomamos consciência desses paradoxos, dificuldades e inconsistências. Embora Berkeley pareça ter em vista sobretudo os erros dos sentidos, ou melhor, a insuficiência alegada das percepções sensíveis para as coisas sensíveis, ele de fato refere-se à especulação em geral. Essa suposta insuficiência do conhecimento sensível acaba por alastrar-se por todas as áreas e o ceticismo a que Berkeley refere-se é um ceticismo genérico. $\mathrm{N}$ os $\mathrm{C}$ omentários filosóficos, ele já expusera a mesma tese de que 0 ceticismo com relação às coisas sensíveis introduz-se subrepticiamente em todas as demais questões filosóficas e joga uma sombra sobre todas elas. A razão, quando pretende corrigir os preconceitos e erros dos sentidos e da natureza, multiplica-os à medida que avançamos em nossa reflexão. N ão se trata, portanto, de um ceticismo limitado à esfera do conhecimento das coisas sensíveis, mas de um ceticismo genérico, que, a partir da desconfiança da percepção sensível e dos instintos naturais, desconfia de tudo. Essa desconfiança faz-se acompanhar da adoção da razão como um princípio superior e mais confiável do que os sentidos ou as inclinações naturais. Com efeito, quando se examina o texto dos Prinápios, não há dúvidas de que o ceticismo que Berkeley pretende refutar é o mais genérico possível, pois o cético alimenta suas suspeitas sobre a metafísica, a filosofia natural, as matemáticas, a moral, a religião, o conhecimento do espírito.

Ainda que o ceticismo considerado por B erkeley seja bastante genérico, deve-se reconhecer que o filósofo confere um destaque ao ceticismo com relação às coisas sensíveis, mais especialmente com relação à matéria (idem, I, p. 87-91). Esse privilégio do tópico do conhecimento sensível das coisas externas já aparece no primeiro parágrafo da "Introdução". M ais adiante (idem, I, p. 40), Berkeley parece sugerir que não acreditar nas evidências sensíveis equivale a não acreditar que podemos conhecer as coisas sensíveis. Com efeito, todas as vezes que a palavra "ceticismo" ocorre nos Prinápios, ela aparece associada ao problema do conhecimento 
sensível das coisas externas. Trata-se, aqui, não de uma outra forma de ceticismo, mas de um tópico particularmente importante no interior desse ceticismo genérico. 0 que talvez explique essa importância do ceticismo com relação à matéria seja sua origem histórica na primeira $M$ editação de D escartes ou talvez suas conseqüências para todo o conhecimento sensível e mesmo para a religião (idem, I, p. 92ss.). U ma outra explicação é a de que o ceticismo a respeito do conhecimento das coisas sensíveis é, como vimos, a porta de entrada para um ceticismo mais geral a respeito de todas as coisas. $C$ abe notar que parece haver uma certa ambiguidade no pensamento de Berkeley: de um lado, o ceticismo acerca do conhecimento das coisas sensíveis é a porta de entrada para o ceticismo; de outro, ele dirá, como veremos mais adiante, o ceticismo acerca das coisas sensíveis é resultado da aceitação da doutrina das idéias abstratas, que, essa sim, gera um ceticismo universal. Q ualquer que seja a explicação correta, está fora de questão que Berkeley dispensa um tratamento mais cuidadoso ao tópico do ceticismo acerca do conhecimento do mundo exterior.

b) N os T rês diálogos entre H ilas e F ilonous, Berkeley oferece-nos duas definições de ceticismo. Conforme a primeira definição, o cético é aquele que duvida de tudo, isto é, aquele que não adota nem o lado positivo, nem o lado negativo de uma questão, mas suspende o juízo entre ambos (BER KELEY, 1998b, I, 173, p. 60-61). D ois aspectos devem ser notados aqui. Em primeiro lugar, digna de nota é a ênfase de Berkeley em que a dúvida deve ser universal, abarcando todo e qualquer ponto particular; se, em uma única questão, qualquer que seja ela, uma pessoa não estiver em dúvida, ela não será cética, ainda que em todas as demais questões ela não assuma nenhuma posição. I sso parece em conformidade com o cuidado que Sexto Empírico tem quando distingue o pirronismo das demais filosofias. A menor diferença, sobre um ponto qualquer, já basta para descaracterizar a outra filosofia como cética, ainda que Sexto possa reconhecer muitas similaridades entre elas (como no caso de A rcesilau, por exemplo). Em segundo lugar, Berkeley não vê nenhuma diferença entre "duvidar" (um ato voluntário, que funda o ceticismo moderno) e "suspender o juízo" (algo que ocorre ao longo da investigação do cético antigo). A o contrário, "duvidar" é precisamente "suspender o juízo", "não afirmar, nem negar", e isso, segundo Berkeley, estaria já embutido no 
sentido usual que "duvidar" tem na língua inglesa. Também nesse ponto, portanto, a definição dada é adequada ao ceticismo antigo, que se caracterizava pela suspensão do juízo, por não aceitar nenhum dos lados de uma questão.

A segunda definição introduz elementos novos na caracterização do cético, pois, segundo essa nova definição, o cético é aquele que "nega a realidade e a verdade das coisas", em particular "das coisas sensíveis" (idem, I, 173, p. 61). Teoremas das ciências e noções intelectuais universais não são questões a respeito das quais o termo "ceticismo" está sendo pensado. A segunda definição, portanto, introduz três novidades em relação à primeira: (1) por um lado, a suspensão de juízo, que consistia na não-adoção de nenhum lado de uma questão, deixa de ser marca característica do cético; o cético, agora, pode ser taxativo e negar peremptoriamente alguma coisa. 0 ra, essa mudança não é nada desprezível, uma vez que se abandona um elemento essencial no itinerário, ou na postura, do cético antigo: o que, para um cético antigo, consistia em uma forma particular de dogmatismo, o assim chamado "dogmatismo negativo" (que Sexto equivocadamente atribuía a Carnéades e C litômaco), passa a ser uma forma de ceticismo. (2) Por outro lado, abre-se mão do caráter universal da posição cética, que dizia respeito a toda e qualquer questão, para focalizar o ponto crucial em uma questão bastante específica, a da realidade das coisas sensíveis. Será considerado um cético, segundo essa nova definição, aquele que professar um único tipo de ignorância, a ignorância a respeito das coisas sensíveis. (3) A última novidade diz respeito à faculdade que seria questionada pelo cético: somente os sentidos e não a razão. Toda a questão seria a de saber se podemos confiar nos sentidos para conhecer as coisas sensíveis, pouco importanto o conhecimento racional que podemos ter de coisas universais. 0 ceticismo antigo pautava-se por questionar tanto a capacidade dos sentidos quanto a da razão, enquanto o ceticismo cartesiano concentrava-se sobretudo na capacidade dos sentidos. Essas três novas características do cético não se encontram presentes em nenhuma forma do ceticismo antigo e aparecem somente com o advento do assim chamado ceticismo cartesiano. Assim, pode-se dizer que, em linhas gerais, na primeira definição, Berkeley oferece uma caracterização do cético antigo e, na segunda, do cético moderno. 
c) Comparação

(i) Em ambas as obras, o ceticismo, segundo Berkeley, adere à razão para combater os sentidos. $M$ as essa adesão não é exatamente igual: nos P rinápios, ela significa sobretudo a adesão à capacidade da razão de formar idéias abstratas e, portanto, mais particularmente, a de separar 0 esse e 0 peraipi das coisas; nos Três diálogos, ela significa somente a capacidade da razão em corrigir os sentidos e inferir as qualidades reais das coisas, bem como sua existência (esse sentido também está presente nos $P$ rinápios).

(ii) Em ambas as obras, o ceticismo contém dois níveis, um genérico, que diz respeito a todas as questões (metafísica, filosofia natural, matemáticas, moral, religião etc.), outro mais específico (somente com relação às coisas sensíveis).

(iii) Em ambas as obras, embora não exatamente da mesma maneira, há um acento no caráter negativo do ceticismo e a suspensão do juízo tem um caráter secundário. N os Prinápios, 0 argumento que leva à suspensão do juízo (BERKELEY, 1998a, I, 14-16) é claramente secundário em relação aos argumentos que mostram ser contraditória e absurda a noção de matéria. N os Três diálogos toda a discussão gira em torno do ceticismo entendido como negação da realidade e da verdade das coisas e não como mera suspensão do juízo, visto que, nessa acepção do termo, nem $\mathrm{H}$ ilas nem Filonous são céticos.

Berkeley parece entender que o ceticismo é uma consequência da "nova filosofia", inaugurada por D escartes e Locke. N esse sentido, devese notar a influência decisiva de $M$ alebranche e Bayle, que teriam mostrado como a "nova filosofia" conduz ao ceticismo, em particular ao traçar a distinção entre qualidades primárias e secundárias e ao introduzir 0 assim chamado "véu das percepções". A ssim, o ceticismo seria uma espécie de "espírito da época" , o resultado natural da filosofia do século XVII.

$M$ as o ceticismo é também uma consequência da filosofia como um todo. Berkeley não se preocupa com a diferença entre céticos antigos e céticos modernos, ainda que pareça reconhecer a diferença entre eles, como mostra a distinção entre dois tipos diferentes de argumentos: argumentos que mostrariam que não podemos conhecer sequer a existência dos objetos externos ou nosso próprio corpo (ceticismo moderno) e argumentos que mostrariam que não podemos saber qual das aparências das coisas corresponde à sua essência (ceticismo antigo). Para Berkeley, 
essa distinção não é particularmente relevante porque ambos os tipos de argumento repousam sobre uma premissa comum inaceitável.

\section{Os diagnósticos de Berkeley}

A refutação do ceticismo de Berkeley traz uma novidade bastante interessante em relação aos seus predecessores. Enquanto os estóicos tentaram refutar os céticos por meio de uma confrontação direta, mostrando que seus argumentos estabeleciam uma verdade sobre as coisas, ou apontando (como fez $\mathrm{H}$ ume posteriormente) a impossibilidade de pôr o ceticismo em prática; enquanto Santo A gostinho e D escartes procuraram mostrar que os argumentos céticos tinham certos limites (por exemplo, as matemáticas) e estabeleciam, eles próprios, uma verdade (a da minha existência), Berkeley procurará fazer um diagnóstico do quadro clínico da filosofia, que conduz inevitavelmente, a seu ver, ao ceticismo. $N$ ão se trata de enfrentar diretamente os argumentos céticos com outros argumentos, mas de mostrar que a problemática cética só se coloca se assumirmos previamente uma determinada doutrina, que é, ela própria, questionável. O ceticismo não seria, desse modo, teoricamente neutro (como ele se pretende), mas, ao contrário, alguém só pode se tornar cético se ele tomar, mesmo que sem o saber, uma decisão filosófica altamente discutível. Para remover a ameaça cética, é preciso identificar o princípio de que ela surge e erradicá-lo. M as qual seria esse princípio que nos conduz ao ceticismo?

Aqui Berkeley parece ter hesitado ou, pelo menos, alterado sua opinião, pois a resposta que encontramos nos P rinápios não é exatamente a mesma que encontramos nos Três diálogos. É preciso reconhecer, desde já, que a resposta dos Três diálogos aparece nos Prinápios com todas as letras, mas não aparece com a importância que terá posteriormente; nem, por outro lado, a resposta dos Prinápios aparecerá nos T rês diálogos, pelo menos não terá nesta última obra, nem de longe, a importância que teve na primeira. Isso nos obrigará, mais uma vez, a examinar em separado cada uma das respostas.

a) N os Prinápios

i) A teoria das idéias abstratas 
N os Prinápios, o grande vilão é a teoria das idéias abstratas. Isso é bastante evidente já na "I ntrodução", em que Berkeley indica aquele que parece ter sido o grande problema da filosofia, desde os seus primórdios. Todas as dificuldades e paradoxos presentes na filosofia não se devem, segundo Berkeley, a uma fragilidade ou imperfeição natural de nossas faculdades, nem à sua finitude (idem, Introdução, 2), mas a um mal uso delas (idem, Introdução, 3). Se o ceticismo triunfa na filosofia, "isso se deve inteiramente a nós mesmos. Primeiramente, levantamos a poeira e, então, reclamamos de que não podemos ver" (idem, Introdução, 4). $\mathrm{N}$ ada mais cartesiano do que essa afirmação sobre o mau uso de nossas faculdades. Entretanto, quando se verifica qual a origem desse mal uso e como 0 corrigir, Berkeley afasta-se completamente de $D$ escartes. 0 diagnóstico a respeito da principal causa do ceticismo, nos Prinápios, é, como já vimos, a doutrina das idéias abstratas, "que parece ter tido uma parte destacada para tornar a especulação intrincada e perplexa, e ter ocasionado erros inumeráveis e dificuldades em quase todas as partes do conhecimento" (idem, Introdução, 6).

É bem verdade que não é sempre claro como e em que sentido a abstração distorce nosso entendimento e desencaminha o em cada caso, mas é obviamente verdade que Berkeley freqüentemente menciona as supostas idéias abstratas para explicar o erro dos filósofos e céticos, bem como invoca sua crítica dessas idéias abstratas para afastar ou eliminar todas as confusões, dificuldades e paradoxos em que a filosofia parece cair. U ma breve espiada nos vários tópicos abordados nos P rinápios deixa esse ponto manifesto.

C omecemos pela metafísica. C omo é bem sabido, o grande problema seria 0 de que a filosofia separou indevidamente o ser das coisas do seu ser percebido. A famosa fórmula de B erkeley, esse est peraipi, viria a corrigir esse defeito crônico da filosofia, que a conduz ao ceticismo. A separação do esse das coisas de seu peraipi, no entanto, já pressupõe a doutrina das idéias abstratas. $N$ ão fosse a adesão, mesmo que implícita, a essa doutrina, não se teria jamais procedido a essa indevida separação. Se analisarmos, portanto, essa questão até sua origem última, não devemos contentar-nos em afirmar somente que o ser das coisas consiste no seu ser percebido; enquanto vigorar a teoria das idéias abstratas, estaremos sempre tentados a incidir no erro de separar esse e peripi e estaremos 
condenados a repetir à exaustão e inutilmente esse est peraipi. "Se examinarmos completamente essa tese [a de que a existência das coisas não depende de seu ser percebido], talvez encontrar-se-á no fundo que ela depende da doutrina das idéias abstratas. Pois pode haver um esforço mais sutil de abstração do que distinguir entre a existência de objetos sensíveis de seu ser percebido, de modo a concebê-las não-percebidas?" (idem, I, 5). É preciso cortar o mal pela raiz, isto é, é preciso denunciar que a separação depende da doutrina das idéias abstratas e que esta é inaceitável.

Do mesmo modo, noções-chave para a explicação da matéria, como extensão (em geral) e movimento (em geral), não são menos produtos da suposta capacidade da mente em produzir ou conhecer idéias abstratas. $\mathrm{N} \mathrm{a}$ medida em que toda extensão ou movimento particular é relativo à mente que os percebe, o filósofo sente- se obrigado a invocar a abstração e a postular uma extensão abstrata e um movimento abstrato para explicar a noção de matéria ou substância corpórea. "Assim, nós vemos em que medida a doutrina de substâncias extensas e móveis que existem fora da mente depende daquela estranha doutrina das idéias abstratas" (idem, I, 11). 0 utra qualidade primária, tida como uma propriedade objetiva, é o número ou unidade. $M$ as, para pôr um ponto final nessa questão, para Berkeley basta mostrar que se trata de uma idéia abstrata (idem, I, 13). Ligada a esse ponto está a distinção entre qualidades primárias e secundárias, tão crucial para o surgimento da filosofia e da ciência modernas. Também aqui Berkeley atribuirá à doutrina das idéias abstratas um papel fundamental na origem de nossos erros, confusões e dificuldades. 0 s filósofos sustentam que as qualidades secundárias existem apenas na mente, enquanto as qualidades primárias existem também no objeto. Entretanto, diz Berkeley, não é possível separar esses dois tipos de qualidades, como pretendem os filósofos. "A gora, se for verdade que aquelas qualidades originais estão insepa ravelmente unidas com as outras qualidades sensíveis, segue-se claramente que elas existem apenas na mente. $M$ a eu desejo que cada um reflita e examine se ele pode, por qualquer abstração de pensamento, conceber a extensão e movimento de um corpo sem todas as outras qualidades sensíveis" (idem, I, 10). 0 que sustenta, portanto, essa tradicional distinção filosófica é, uma vez mais, a doutrina das idéias abstratas.

A discussão do conhecimento feita por Berkeley divide-se em dois campos, o conhecimento das idéias e o conhecimento das mentes. 0 
conhecimento das idéias divide-se em dois outros campos, o da filosofia natural e 0 das matemáticas. $N$ esses dois campos, a doutrina das idéias abstratas será a grande fonte do ceticismo reinante.

Com relação à filosofia natural, os céticos parecem triunfar, na medida em que eles exibem argumentos que depreciam nossas faculdades, que revelam nossa ignorância, ao mostrarem nossa insuperável cegueira com relação à natureza verdadeira e real das coisas. 0 ponto principal em que os céticos insistem, e parecem triunfar, é o de que a constituição interna e oculta das coisas é inacessível para nós, por qualquer meio por que a tentemos descobrir. A essência real, as qualidades internas, as minúsculas partes que compõem as coisas, tudo isso estaria além de nossas capacidades cognitivas (idem, I, 101).

Por que há pelo menos esse triunfo aparente dos céticos? Por que parece que ignoramos a natureza das coisas? Berkeley investiga mais minuciosamente a ciência moderna, com seus princípios mecânicos, particularmente a atração. Em sua crítica a $\mathrm{N}$ ewton, Berkeley rejeita as noções de espaço absoluto, movimento absoluto e tempo absoluto, por que repousam sobre a inaceitável doutrina das idéias abstratas (idem, I , 9798, 110-117). É famosa a passagem em que Berkeley afirma que "tempo, espaço e movimento, se tomados em particular ou concretamente, são 0 que todo mundo sabe; mas tendo passado pelas mãos de um metafísico, tornam-se muito abstratos e finos para serem apreendidos por homens de sentido ordinário" (idem, I, 97).

Com relação às matemáticas, não encontraremos nenhuma surpresa no diagnóstico de Berkeley. Embora as matemáticas contenham demons trações claras e certas, deduzindo a partir de seus teoremas com alto grau de evidência, elas não estão completamente isentas de erros. C ertas máximas equivocadas, implicitamente aceitas, acabam por produzir erros em cada um de seus ramos. "Para ser franco, suspeitamos de que os matemáticos estão, bem como os outros homens, afetados pelos erros que surgem da doutrina das idéias gerais abstratas e da existência de objetos fora da mente" (idem, I, 118). Sustenta-se, no caso da A ritmética, que seus objetos, os números, são idéias abstratas (idem, I, 119-122). No caso da Geometria, cujo objeto é a extensão, sustentou-se sua infinita divisibilidade, o que pressupõe que se está lidando com uma idéia abstrata de extensão (idem, I, 123-132). 
0 caso parece mudar quando se trata do conhecimento da mente, não somente porque, segundo Berkeley, nosso conhecimento nesse campo não é tão deficiente quanto normalmente se supõe, mas também porque 0 defeito, se defeito há, se deve a uma exigência absurda e sem-sentido. Os filósofos que se queixam e dizem que não conhecemos nossas próprias mentes, alegam para isso o fato de que não temos idéia de nossas mentes, que não temos uma idéia de sua natureza. $M$ as, bem entendido, idéia e mente são coisas tão díspares que é um disparate exigir que se tenha uma idéia da mente (idem, I, 135). N esse caso preciso, a doutrina das idéias abstratas não é a principal causa do ceticismo. Entretanto, ela não deixará de desempenhar um papel importante, ainda que secundário, nesse campo do conhecimento. Com efeito, Berkeley afirma que "não será demasiado acrescentar que a doutrina das idéias abstratas teve uma parte não pequena ao tornar essas ciências, que versam particularmente sobre coisas espirituais, intrincadas e obscuras" (idem, I, 143).

Por fim, cabe mencionar brevemente que também na moral a doutrina das idéias abstratas terá um papel pernicioso. As idéias de felicidade, bondade, justiça, virtude são perfeitamente inteligíveis para todos nós; mas se pretendermos separá-las de todos os prazeres particulares, de todas as coisas boas, de qualquer idéia precisa de justiça e virtude, nesse caso estaremos (supostamente) formando noções gerais abstratas e arruinando aquela que é a mais útil parte do conhecimento, a moral (idem, I, 100). Finalmente, na religião, uma fonte principal é a doutrina da matéria ou da substância corpórea (idem, I, 92-96), mas essa doutrina, como já vimos, repousa na doutrina das idéias abstratas.

ii) A substância material

Já vimos que, nos P rinápios, Berkeley dispensa um tratamento especial ao conhecimento das coisas sensíveis e que é nesse contexto que o termo "ceticismo" aparece explicitamente. $\mathrm{N}$ esse tópico, o grande responsável pelo surgimento do ceticismo é a teoria de que a realidade ou a existência das coisas sensíveis é independente da sua percepção por uma mente. Isso que supostamente existe fora da mente é a matéria ou substância corpórea e será a causa de todos os problemas relativos ao conhecimento das coisas não-pensantes (isto é, as idéias). "N osso conhecimento delas [as idéias] tem sido muito obscurecido e confundido e temos sido levados a erros muito perigosos, ao supor a dupla existência dos objetos dos sentidos, 
um inteligível, ou na mente, o outro real e fora da mente: por meio do que se supõe que as coisas não-pensantes têm uma subsistência natural delas próprias, distinta do ser percebidas por espíritos. Isso que, se não me engano, foi mostrado que é a noção mais infundada e absurda, é a própria raiz do ceticismo" (idem, I, 86). A "Introdução" já havia anunciado, desde o princípio, que o grande mal que causava o ceticismo era a desconfiança de nossos sentidos, como se eles não fossem capazes de nos fazer conhecer as próprias coisas. $\mathrm{N}$ o momento mesmo em que começamos a pôr em dúvida a evidência dos sentidos, a porta para o ceticismo está aberta e não há mais como evitá lo (idem, Introdução, 1). Já notei como outra passagem (idem, I, 40) sugeria que desconfiar dos sentidos significava, em primeiro lugar, desconfiar do conhecimento das coisas sensíveis interpretadas à maneira dos filósofos, isto é, como matéria.

Trata-se aqui de uma hesitação ou ambiguidade de Berkeley? Já apontei qual a dificuldade de interpretação aqui: se de um lado o ceticismo com relação ao mundo exterior é somente mais um produto da aceitação da doutrina das idéias abstratas, de outro o ceticismo parece ter origem na desconfiança que temos do conhecimento das coisas sensíveis. Poder-seia realmente pensar que B erkeley não indica claramente qual a origem do ceticismo, mas tal suposição talvez seja desnecessária. Por um lado, cabe notar novamente que a noção de substância material é, ela própria, dependente da doutrina das idéias abstratas (idem, I , 5, 11). N esse sentido, menos do que uma hesitação ou ambiguidade, trata-se de um caso em que 0 desenvolvimento da doença cética é particularmente dramático e seu tratamento exige uma investigação mais detalhada. Descobrir a importância da noção de substância material para o sucesso do ceticismo não conflita com a importância da doutrina das idéias abstratas, mas estende essa doutrina de modo surpreendente. A lém disso, pode-se pensar que 0 caso das coisas sensíveis é, não somente o mais importante, mas também o primeiro (no sentido temporal) em que a aceitação das idéias abstratas se manifesta. Por isso mesmo, é supondo uma existência absoluta, distinta do ser percebido, que o ceticismo se insinua para dentro da filosofia. (Por outro lado, se recorrermos às definições dadas nos T rês diálogos, podemos conciliar esses dois diagnósticos sem maiores dificuldades. Se a doutrina das idéias abstratas consiste na fonte última de um ceticismo generalizado, com relação a todos os campos do saber, a doutrina 
materialista será responsável pelo ceticismo em um tópico muito específico, o da existência e da realidade das coisas sensíveis. N o primeiro caso, trata-se do ceticismo segundo a sua primeira definição (oferecida nos Três diálogos), que envolve todas as questões; no segundo caso, trata se do ceticismo em seu sentido mais limitado, dado pela segunda definição (oferecida nos Três diálogos) e que concerne somente às coisas sensíveis.) N ão há nenhuma tensão, portanto, entre esses dois diagnósticos nos P rinápios.

b) N os T rês diálogos

Talvez caiba mencionar, antes de mais nada, que, nos Três diálogos, a crítica à doutrina das idéias abstratas passa a desempenhar um papel bem menos importante daquele desempenhado nos Prinápios. Ela aparece algumas vezes no texto, mas nunca com a importância decisiva que a ela fora atribuída anteriormente. $A$ abstração é, com frequência, uma espécie de recurso último invocado pelos filósofos a fim de defenderem suas posições diante das críticas berkeleyanas. Por exemplo, quando Filonous (Berkeley) procura mostrar que o calor intenso existe apenas na mente, já que ele é indissociável da dor, $\mathrm{H}$ ilas defende-se tentando abstrair a sensação de calor da sensação da dor; Filonous, então, argumenta que tal abstração é impossível. Em alguns casos, como na discussão da Física newtoniana, a crítica das idéias abstratas terá exatamente o mesmo papel que antes. $R$ aras vezes, entretanto, Berkeley dirá que a suposição da abstração é a causa ou a fonte primeira do ceticismo. Ao contrário, ao pesar as vantagens do imaterialismo para o conhecimento humano, nenhuma ou quase nenhuma menção será feita à abstração (BER KELEY, 1998b, III , 257-258, p. 138-139). Ele, de fato, chega a sugerir uma vez que a abstração tem papel fundamental para a origem do ceticismo, mas a comparação entre o número de vezes que a doutrina da abstração é mencionada como a causa de erros e equívocos e o papel atribuído à abstração nos P rinápios e nos Três diálogos causa inegável impacto.

De outro lado, a crítica ao materialismo adquire uma importância ainda maior do que a que já tivera nos Prinápios, pois a noção de que somente a suposta coisa corpórea é real gera um ceticismo universal e não apenas com relação ao conhecimento sensível das coisas corpóreas. “ $N$ ão é aquela oposição a todas as ciências, aquele frenesi dos céticos antigos e modernos fundados no mesmo fundamento? 0 u você pode produzir um argumento contra a realidade das coisas corpóreas ou em defesa 
daquela admitida ignorância completa de suas naturezas que não pressuponha que sua realidade consiste em uma existência externa absoluta? C om base nessa suposição, realmente, as objeções a partir da mudança de cores no pescoço de um pombo, ou as aparências de um remo quebrado na água, devem ser admitidas como tendo força" (idem, III, 258, p. 139; sem grifos no original).Todas as ciências, portanto, são presas fáceis do ceticismo, uma vez que se admita uma existência externa absoluta; pois, tendose aceito essa existência, os argumentos céticos tornam-se imediatamente fortes, de fato decisivos.

Berkeley mostra nos como o imaterialismo, que recusa essa existência externa absoluta, protege as várias ciências do ataque do ceticismo. $\mathrm{Na}$ filosofia natural, a crença na matéria conduz-nos a uma infinidade de obscuridades e contradições: sobre a continuidade, divisibilidade, homogeneidade, gravidade da matéria; sobre a operação da matéria sobre a matéria: como uma move a outra, como um ser passivo pode agir sobre outro; sobre a relação das leis do movimento com as qualidades secundárias. A adoção do imaterialismo evita todas essas dificuldades. $N$ as matemáticas, todas as dificuldades concernentes à infinita divisibilidade da extensão são geradas pela suposição de que essa tem uma existência externa absoluta. $\mathrm{N} \mathrm{a}$ metafísica, as dificuldades com relação às entidades abstratas, formas substanciais, princípios materiais, naturezas plásticas, substância e acidente, a maneira de operação da matéria sobre o espírito, também são derivadas da suposição da matéria. Finalmente, também na moral, e mesmo na religião, a recusa da matéria traz inúmeras vantagens: põe-nos mais perto de D eus, ao eliminar esse dispensável e imaginário intermediário, que é a matéria (idem, III, 257258, p. 138-139). Berkeley atribui todas as dificuldades, em cada uma dessas ciências, à noção de matéria.

c) Comparação: muita coisa do que já estava presente nos Prinápios reaparece nos T rês diálogos; na verdade tudo é neles retomado e nenhuma novidade aparece. Entretanto, os Três diálogos não são somente uma retomada simplificada dos Prinápios, pois percebe-se o surgimento de uma outra perspectiva sobre o ceticismo a partir dos mesmos elementos. A diferença está nos pesos atribuídos aos fatores que geram o ceticismo: enquanto nos Prinápios a abstração desempenhava um papel fundamental, este caberá, nos Três diálogos, à matéria. Berkeley, portanto, reformula sua apreciação sobre a origem última do ceticismo. 


\section{Duas estratégias de combate ao ceticismo}

$\mathrm{N}$ ós veremos agora que esses diferentes diagnósticos determinam diferentes estratégias de combater o ceticismo.

a) $O$ enfrentamento direto dos Prinćpios. Q ual a melhor estratégia para refutar o cético? A resposta dos P rinápios é corajosa e ousada: enunciar tão claramente quanto possível, e em poucas linhas, qual é a verdade; a luz da verdade, por si só, eliminaria as trevas do ceticismo. 0 u talvez: para eliminar o ceticismo, basta falar com sentido e toda a discussão desaparece tão logo anexemos sentido às nossas palavras. " $N$ ada parece mais importante, para erigir um sistema firme de conhecimento sólido e real, que possa ser uma prova contra os assaltos do ceticismo, do que colocar o princípio em um explicação distinta do que se significa por "coisa", "realidade", "existência": pois em vão disputaremos com relação à existência real das coisas, ou pretenderemos ter algum conhecimento delas, enquanto não tivermos fixado o significado daquelas palavras" (BER KELEY, 1998a, I, 89). É de fato surpreendente, e por isso mesmo freqüentemente notado por comentadores, que toda a metafísica de Berkeley já está exposta nos primeiros seis ou sete parágrafos (duas ou três páginas) e que os próximos 26 estabeleçam definitivamente 0 ponto em questão (cerca de 11 páginas). Essa pressa, por assim dizer, resulta da aplicação rigorosa de sua estratégia de combate ao ceticismo. Se quisermos afastar a ameaça do ceticismo, o melhor é não a deixar surgir, o melhor é abafá-la desde o princípio, mostrando claramente o que entendemos por "coisa", "realidade" e "existência", e assim mostrando a verdade que obstrui o ceticismo.

A escolha do gênero também não é arbitrária. Se vamos expor a verdade, nua e crua, sem artifícios e maiores delongas, então o gênero do tratado é o mais adequado. 0 tratado permite justamente dizer de modo pleno a verdade sem argumentar mais minuciosamente com o adversário, ao menos em um primeiro momento, postergando assim a discussão das objeções e dúvidas, e é indiferente ao processo de descobrimento da verdade.

Se assim fizermos, então a verdade resplandecerá claramente diante de nosso ol hos e o ceticismo estará afastado. N enhuma dúvida pairará no ar a fim de macular o brilho da verdade. Exibida assim para nós antes de 
qualquer dúvida possível (as dúvidas e as objeções só surgirão, no texto, depois de enunciada a verdade), a verdade será transparente. $\mathrm{N}$ ão é à toa que Berkeley, seguindo essa estratégia de combate direto do ceticismo ao mostrar imediatamente a verdade nua e crua, repetirá com frequência que "nós facilmente perceberemos que...", que "é óbvio que...", que "é evidente que...". Tampouco é mera coincidência que os P rinápios comecem com "É evidente que..." (idem, I , 1). "Algumas verdades, diz Berkeley, são tão óbvias e próximas da mente que um homem precisa somente abrir seus olhos para vê-las" (idem, I, 6). São verdades desse tipo aquelas que Berkeley pretende estabelecer e que são fundamentais na filosofia.

$\mathrm{N}$ ão se deve confundir aqui essa obviedade das verdades fundamentais, a que Berkeley constantemente se refere, com a introspecção que B erkeley pede que cada leitor faça em diversos pontos de seu texto. A origem dessa possível confusão é que, com freqüência, a introspecção revela-nos facilmente o ponto que Berkeley estebelece (pelo menos, isso é assim para Berkeley). $M$ as deve-se notar que a introspecção pode ou não nos dar algo evidente ou óbvio - e algo óbvio ou evidente pode ser percebido de outra maneira que não pela introspecção. A obviedade, evidência ou transparência dessas verdades não se deve, a meu ver, à intros pecção, mas à estratégia de Berkeley, vale dizer, à sua enunciação antes mesmo que as dúvidas céticas possam assaltar o nosso conhecimento. $M$ ais do que isso, a sua obviedade impede que as dúvidas céticas possam surgir e ocultar a verdade clara e evidente.

No entanto, é preciso ver que essa estratégia foi preparada por uma "Introdução" sobre a linguagem e as idéias abstratas. "A fim de preparar a mente do leitor para uma concepção mais fácil do que se segue, é apropriado pressupor alguma coisa, como uma introdução, com relação ao uso e abuso da linguagem" (idem, Introdução, 6). Em certo sentido, portanto, a enunciação imediata da verdade e do sentido das palavras fazse preceder por uma consideração acerca da linguagem que mostra como surge a perniciosa doutrina das idéias abstratas. Sem uma contundente crítica a essa perniciosa doutrina, a força mesma da verdade e a destruição do ceticismo estarão em risco. Entretanto, se a pusermos de lado, então a estratégia berkeleyana terá livre caminho para obter o desejado sucesso.

b) Entretanto, a estratégia fracassou redondamente e Berkeley foi visto como um cético. Q uais são as razões do fracasso? Talvez não tenha 
preparado suficientemente o leitor para receber as novas doutrinas. Por um lado, a crítica das idéias abstratas não cumpriu adequadamente sua função (mesmo H ume, que dirá que essa foi uma das princípais descobertas na filosofia, não se convencerá de que Berkeley não é um cético). $E$, por outro lado, ao invés de facilitar a aceitação do imaterialismo, sua exposição franca e direta causa uma forte reação negativa. 0 s preconceitos em favor da matéria são muito mais fortes e enraizados do que pensava B erkeley; a exposição direta do imaterialismo, longe de erradicá los, suscita sua irritabilidade e só os fortifica. A reação é tão grande que, só de ouvir a tese imaterialista, o livro é ridicularizado e rejeitado, mesmo sem ser lido. Essa seria uma explicação psicológica, mas que é da maior relevância para Berkeley. " $M$ as você não é sensível, $H$ ilas, que duas coisas devem estar presentes para eliminar todo escrúpulo e produzir um assentimento pleno na mente? D eixe um objeto visível ser posto na luz mais clara; contudo, se houver alguma imperfeição na visão, ou se o olho não estiver dirigido para ele, ele não será visto distintamente. E apesar de uma demonstração jamais estar tão bem fundada e justamente proposta; contudo, se houver uma mancha de preconceito ou uma tendência equivocada do entendimento, pode ser esperado que ele de repente perceba claramente e adira firmemente à verdade? $\mathrm{N}$ ão, é preciso tempo e esforços: a atenção deve ser desperta e detida por uma freqüente repetição da mesma coisa colocada sob luzes ora muitas vezes iguais, ora muitas vezes diferentes" (BER KELEY, 1998b, II, 223, p. 108). Berkeley adotará, portanto, uma outra estratégia nos T rês diálogos. 0 procedimento lento e cuidadoso dos Três diálogos substituirá a enunciação imediata da verdade como ataque franco e direto ao ceticismo. Berkeley, com efeito, repetirá à exaustão seus argumentos, voltará com freqüência aos mesmos pontos, insistirá nas mesmas perguntas, pedirá a $\mathrm{H}$ ilas que exponha de novo suas opiniões, dará a oportunidade para $\mathrm{H}$ ilas rever sua definição de matéria, para analisar novamente to dos os argumentos empregados. A quilo que pode parecer uma mera e enfadonha repetição de um mesmo argumento nada mais é do que a erradicação progressiva de um preconceito e de uma miopia. Aquilo que pode parecer uma monótona discussão de todos os possíveis sentidos do termo "matéria" não é senão o exame de uma questão sob todas as suas luzes a fim de aniquilar esse mesmo preconceito. A verdade não se impõe imediatamente por sua 
evidência própria; mesmo se exposta claramente, ela não será vista. É preciso também, não somente acostumar nosso olho à luz, mas dirigi-lo para onde a verdade está.

Essa mudança na estratégia implica a mudança do gênero literário adotado. Em vez do tratado, Berkeley preferirá agora o gênero do diálogo. A escolha desse gênero deve-se ao seu aspecto pedagógico, uma vez que Berkeley não quer ser outra vez mal-compreendido? Certamente, pois ele permite que o materialista exponha sua doutrina e a defenda de todas as maneiras possíveis; permite também que 0 materialista examine e critique 0 imaterialismo e desfaça todos os mal-entendidos. 0 lento procedimento de assentimento à verdade pede que o leitor se desfaça primeiramente de seus preconceitos para depois contemplar progressivamente a verdade. $Q$ ual é a nova estratégia de B erkeley? Primeiro, mostrar como o materialismo conduz inevitavelmente ao ceticismo e aos paradoxos, para só depois introduzir, e lentamente, a "verdade" (um pouco no segundo diálogo e inteira só no terceiro).

$M$ as há muito mais do que isso nessa escolha pelo diálogo, pois nem todo diálogo é pedagógico. A razão de fundo, creio, para essa mudança de gênero, jaz na alteração de toda a estratégia de combate ao ceticismo, que leva em conta não somente as dificuldades naturais de aceitação da verdade do imaterialismo, mas também as dificuldades filosóficas envolvidas na questão. Em particular, Berkeley acreditava que o ceticismo seria refutado pela clara enunciação do imaterialismo, agora ele crê que o ceticismo será refutado à medida que nos tornarmos conscientes de sua dependência de uma teoria filosófica muito peculiar e questionável, a de que a existência das coisas não depende de seu ser percebido por alguma mente. $O$ ra, a nuance aqui é pequena, mas significativa. É de fundamental importância que se perceba claramente em que sentido o ceticismo é um produto filosófico; só quando tivermos essa plena consciência é que poderemos rejeitá-lo. Por isso, o trabalho inicial é o de conscientização dessa dependência do ceticismo com relação a uma doutrina filosófica peculiar, a da existência da matéria. $\mathrm{N}$ a medida em que o ceticismo é uma espécie de parasita dessa doutrina filosófica, ele pode ser eliminado ao se eliminar o hospedeiro, a saber, o materialismo. Toda a ênfase de Berkeley será posta nesse aspecto: o ceticismo depende, para a sua existência, do materialismo e é preciso mostrar detalhadamente como se 
dá essa dependência. 0 ra, o diálogo permite extrair, da boca do próprio materialista, a confissão de que o ceticismo se segue como uma consequência inevitável de seus princípios materialistas. A escolha do gênero do diálogo, portanto, está ligada ao caráter parasitário do ceticismo, que se hospeda no materialismo.

Antes de deixarmos este tópico, eu gostaria de fazer uma observação que não é de menor importância sobre 0 uso berkeleyano do termo "idéia". N os Princípios, o termo é introduzido logo no início, com seu significado filosófico, a saber, tudo aquilo que é objeto imediato da mente; por exemplo, já na primeira sentença do primeiro parágrafo (BER KELEY, 1998a, I, 1), as sensações impressas nos sentidos são chamadas de "idéias" e as coisas sensíveis, de coleções de idéias; logo a seguir (idem, l, 2) equiparam-se "idéias" e "objetos do conhecimento". Berkeley, ansioso por estabelecer logo a verdade das coisas, emprega 0 termo "idéia" com esse sentido filosófico para enfatizar que tudo o que existe ou são mentes ou são "idéias" dependentes destas. O ra, os T rês diálogos são bastante cuidadosos nesse ponto. Embora ocorra uma ou duas vezes antes do final do primeiro diálogo, em falas de Filonous, ele é introduzido por H ilas somente quando ele começa a confessar o seu ceticismo, quando começa a reconhecer que, segundo os seus prinápios, ele tem que negar a existência das coisas sensíveis e não admitir senão "idéias", que, no seu entender, não são reais por não serem independentes da mente. É H ilas quem explicita ou atribui o significado filosófico do termo, ao distinguir entre aquilo que se passa em nós e o objeto externo representado pela "idéia". "Para dizer a verdade, Filonous, eu penso que há dois tipos de objetos, um percebido imediatamente, que é igualmente chamado de idéias; o outro são coisas reais ou objetos externos percebidos por meio das idéias, que são suas imagens ou representações. A gora eu reconheço, idéias não existem fora da mente; mas o último tipo de objeto existe" (BER KELEY, 1998b, I, 203, p. 89). Essa diferença, em um termo-chave, não deve passar desapercebida. N os Três diálogos, Berkeley quer deixar bem claro que são os filósofos que definem e usam o termo de maneira peculiar; ele apenas os segue nesse ponto (cf. também BER KELEY, 1998b, III, 262, p. 142-143), pois o termo favorece 0 imaterialismo. 0 cuidado aqui não é somente retórico, como se a única intenção de Berkeley fosse distanciar-se do "idealismo", como se ele 
apenas quisesse chamar a atenção para 0 fato de que ele não é um "idealista", mas um "realista", pois ele admite a realidade das coisas sensíveis. Essa é certamente uma de suas preocupações. M as há ainda uma outra, tão ou mais importante do que essa. Ele também quer mostrar que o "idealismo" (ou ceticismo) é uma consequência dos princípios materialistas de $\mathrm{H}$ ilas: é H ilas quem é forçado a cunhar esse sentido filosófico do termo.

c) Comparação: nada mais diferente do que as estratégias empregadas por Berkeley para combater o ceticismo. Enquanto os Prinápios optam por dissipar a névoa do ceticismo ao fazer brilhar a luz e o calor do sol desde os primeiros instantes da manhã, os Três diálogos deixam que as brumas do ceticismo surjam do materialismo, para depois desviar a atenção da matéria para as mentes, em particular a mente divina. A diferença de estratégia resulta, de um lado, de uma apreciação melhor da força do preconceito em favor da matéria (aspecto psicológico, por assim dizer) e, de outro, de uma melhor apreciação da dependência do ceticismo em relação à noção de matéria, como veremos no próximo tópico.

\section{Conclusão}

D eve-se reconhecer que a filosofia de Berkeley presente nas duas obras é praticamente a mesma. $\mathrm{M}$ as corre-se 0 risco de, dada essa grande concordância e harmonia das obras, ignorar al gumas diferenças significa tivas entre elas. Procurei ressaltar como Berkeley oferece, nos T rês diálogos, concepções mais precisas e adequadas do ceticismo, como as estratégias de combate ao ceticismo chegam mesmo a serem opostas e que essa mudança reflete não somente uma compreensão melhor de como estabelecer a verdade e persuadir o adversário, mas também uma compreensão melhor da natureza do problema levantado pelo ceticismo. I sso se tornou claro quando, ao analisarmos os diagnósticos oferecidos por Berkeley, notamos uma mudança, talvez pequena, mas de al gum significado filosófico, no foco: 0 alvo principal deveria redirecionar-se da crítica da doutrina das idéias abstratas para a crítica da noção de matéria. Se aceitarmos sem maiores cuidados a indicação de Berkeley, como o fizeram muitos comentadores, poderemos deixar escapar al gumas novidades introduzidas 
pelos T rês diálogos e assim não compreender a contribuição da última obra à filosofia de Berkeley. $\mathrm{N}$ aturalmente, como eu disse no início, todas essas hipóteses de leitura devem ser analisadas com mais rigor e detalhe. Em particular, devemos examinar os tipos de argumentos que Berkeley emprega contra o ceticismo, em uma e em outra obra, para examinarmos com o devido cuidado as sugestões aqui formuladas.

${ }^{1}$ Entretanto, Berkeley foi visto como um cético por muitos filósofos, entre eles $D$ avid $H$ ume. Charles (2003) mostra detalhadamente como surgiu, nas Luzes francesas, essa distorção do pensamento de Berkeley.

2 Stoneham (2002), defendendo o interesse de uma interpretação específica dos T rês diálogos, tece comentários interessantes sobre al gumas diferenças entre essa obra e os P rinćpios.

\section{Referências bibliográficas}

BER KELEY, G. 1998a. A Treatise C oncerning the Prinaiples of $H$ uman $\mathrm{K}$ nowledge. Ed. by J. D ancy. N ew York: $\mathrm{O}$ xford U niversity. . 1998b. Three D ialogues between H ylas and Philonous. Ed. by J. $\mathrm{D}$ ancy. $\mathrm{N}$ ew York: $\mathrm{O}$ xford U niversity.

BER M AN , D. 1996. G eorge B erkeley: Idealism and the M an. 0 xford: Clarendon.

CH AR LES, S. 2003. B erkeley au siède des lumières: immatérialisme et scepticisme au XVIIle siècle. Paris: $V$ rin.

ST O N EH AM , T. 2002. Berkeley'sW orld: An Examination of the Three $D$ ialogues. 0 xford: 0 xford $U$ niversity. 